\title{
Tectonics, Climate and Topography: Oxygen stable isotopes and the early Eocene growth of the Pyrenees
}

Louis Honegger ${ }^{1}$, Thierry Adatte ${ }^{2}$, Jorge E. Spangenberg ${ }^{3}$, Miquel Poyatos-Moré ${ }^{4}$, Alexandre Ortiz ${ }^{5,6}$, Magdalena Ellis Curry ${ }^{7}$, Damien Huyghe ${ }^{8}$, Cai Puigdefàbregas ${ }^{9}$, Miguel Garcés ${ }^{10}$, Andreu Vinyoles ${ }^{10}$, 5 Luis Valero ${ }^{1}$, Charlotte Läuchli ${ }^{11}$, Andrés Nowak ${ }^{1}$, Andrea Fildani ${ }^{12}$, Julian D. Clark ${ }^{13}$, Sébastien Castelltort ${ }^{*}$

${ }^{1}$ Department of Earth Sciences, University of Geneva, Rue des Maraîchers 13, 1205 Geneva, Switzerland ${ }^{2}$ Institut of Earth Sciences, Géopolis, University of Lausanne, 1015 Lausanne, Switzerland

$10{ }^{3}$ Institute of Earth Surface Dynamics (IDYST), Géopolis, University of Lausanne, 1015 Lausanne, Switzerland

${ }^{4}$ Department of Geosciences, University of Oslo, Sem Sælands vei 1, 0371 Oslo, Norway

${ }^{5}$ Université de Pau et des Pays de l'Adour, LFCR, UMR5150, 64000 Pau, France

${ }^{6}$ TOTAL, CSTJF, 64018, Pau Cedex, France

$15{ }^{7}$ Department of Earth and Atmospheric Sciences3507 Cullen Blvd.University of Houston

${ }^{8}$ INES ParisTech, PSL University, Centre de Géosciences, 35 rue St Honoré, 77305, Fontainebleau, Cedex, France

${ }^{9}$ Department of Earth and Ocean Dynamics, University of Barcelona, C/ Martí i Franquès, s/n, 08028 Barcelona, Spain

$20{ }^{10}$ Department of Earth and Ocean Dynamics \& Geomodels Research Institute, Faculty of Earth Sciences, Universitat de Barcelona, Spain

${ }^{11}$ Freie Universität Berlin, Division of Tectonics and Sedimentary Geology, Malteserstr. 74-100, 12249

Berlin, Germany

${ }^{12}$ The Deep Time Institute, P.O. Box 27552, Austin, Texas 78755-7552, USA

$25{ }^{13}$ Equinor Research Center, 6300 Bridge Point Parkway, Building 2, Suite 100, Austin, Texas, USA

Correspondence to: Sébastien Castelltort (sebastien.castelltort@unige.ch)

\section{Supplementary Material}




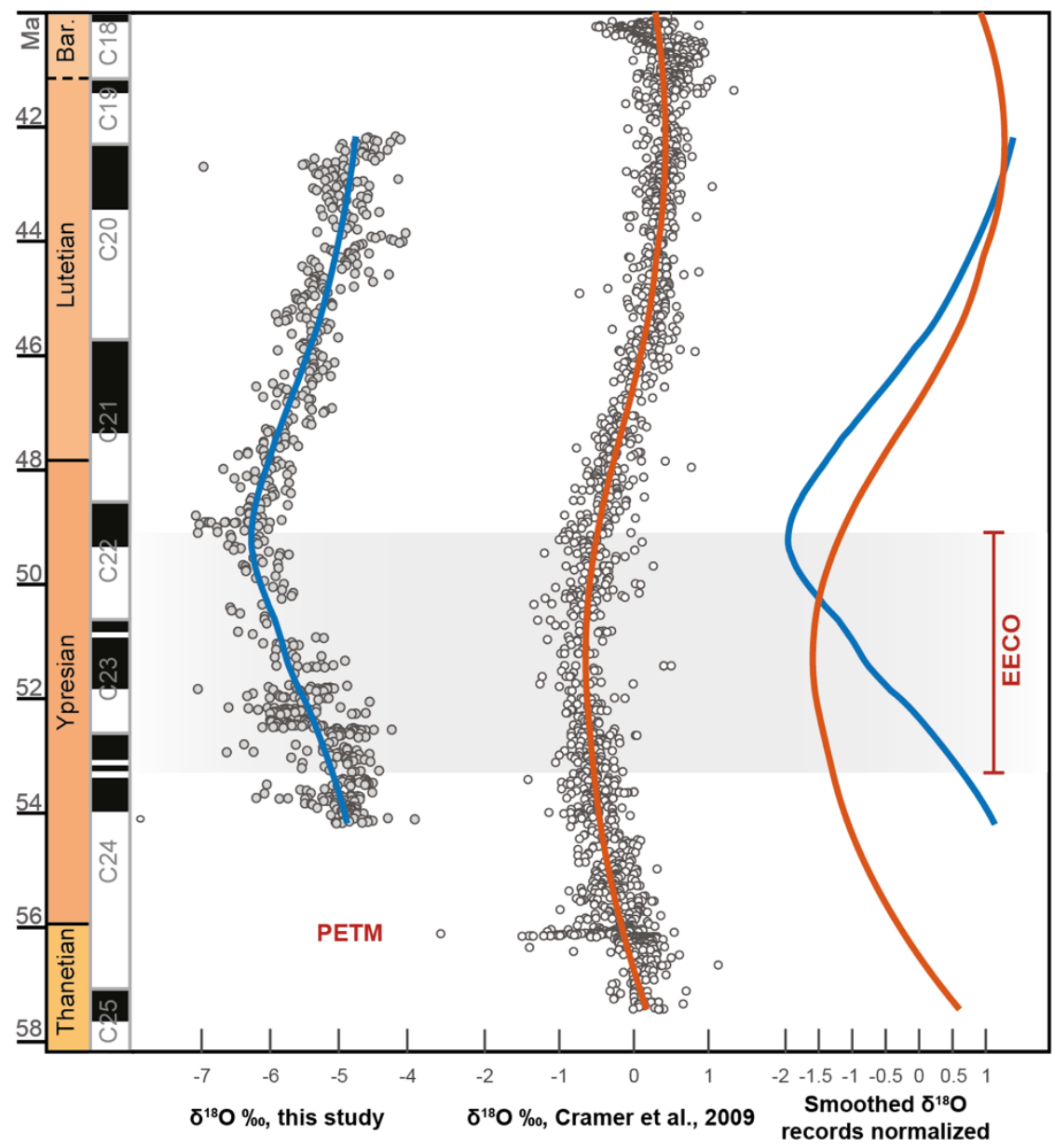

30 Figure S1 - Pyrenean, global (Cramer et al., 2009), and smoothed and normalized $\delta 180$ records 


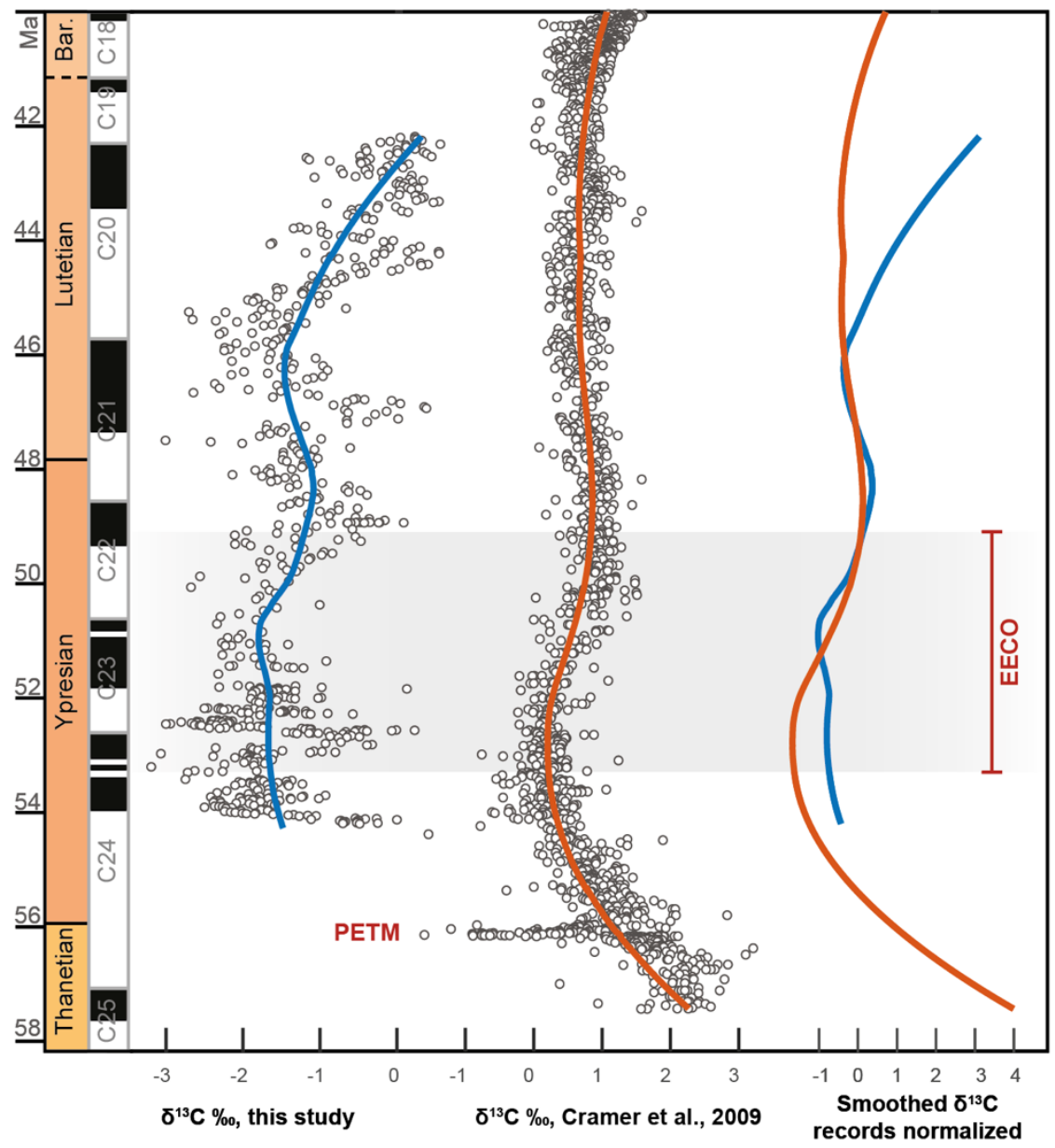

Figure S2 - Pyrenean, global (Cramer et al., 2009), and smoothed and normalized $\delta 13 C$ records 

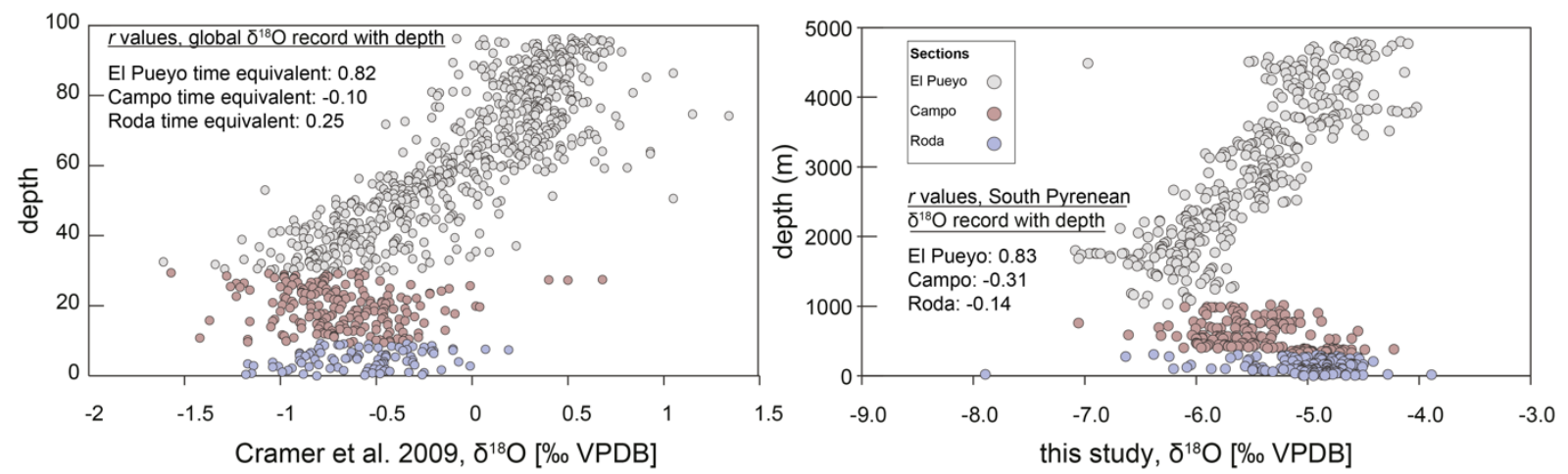

Figure $S 3$ - Cramer et al. (2009) and this study $\delta 180$ records with depth. For the Global record, Pearson correlation coefficient (r) between $\delta 180$ and depth was calculated based on the south Pyrenean sections time-equivalent. Cramer et al. (2009) data set was plotted with an incremental depth of 0.1 . 


\section{EI Pueyo}

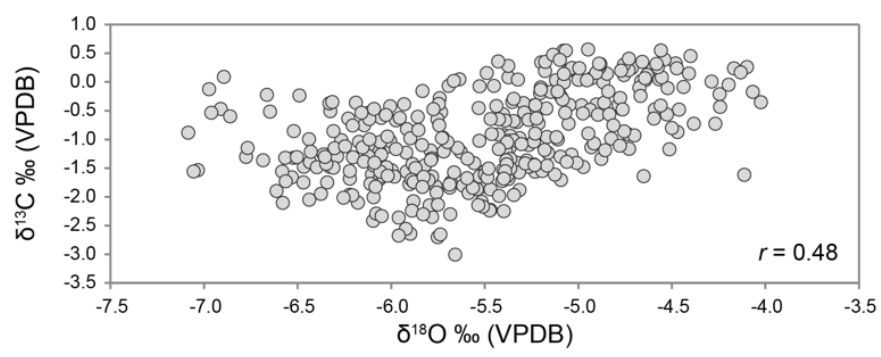

Campo

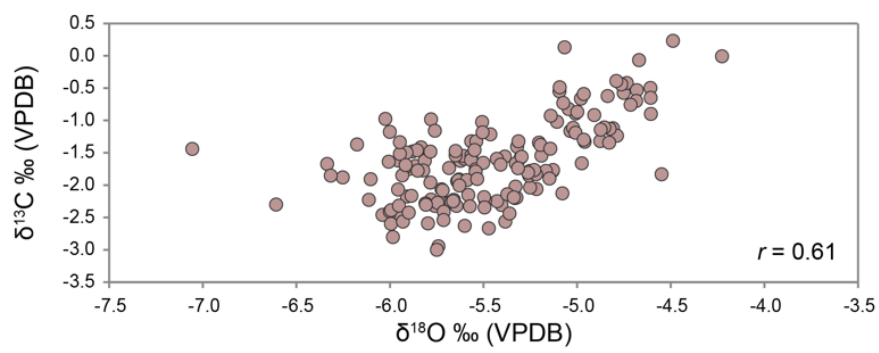

Roda

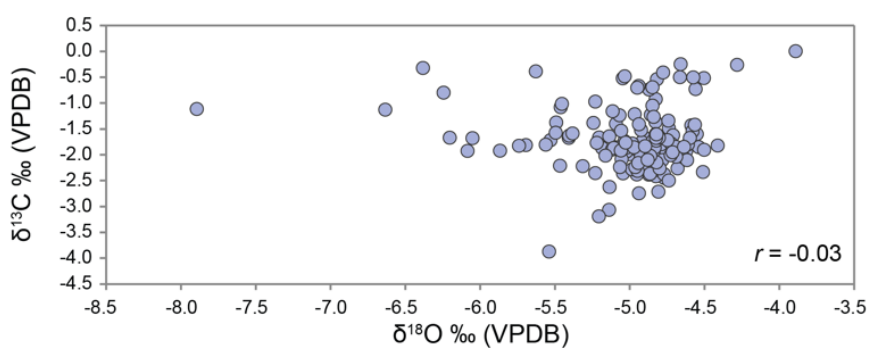

All

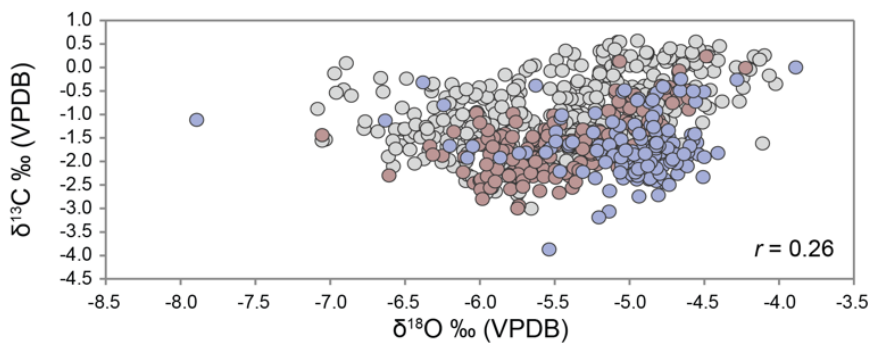

Figure $\mathrm{S} 4-\delta 13 \mathrm{C}$ v. $\delta 180$ plots of all studied sections from the south Pyrenean basins. 